\title{
EDXRF Spektrometresi Kullanılarak Pileki Mağarası'ndan Çıkarılan Pileki Taşı ve Toprak Örneklerinde İz Elementlerinin Belirlenmesi ${ }^{\dagger}$
}

\author{
Serdar DİZMAN \\ Recep Tayyip Erdoğan Üniversitesi, Fen Edebiyat Fakültesi, Fizik Bölümü, Rize, Türkiye
}

Geliş Tarihi: 07.08.2017

Sorumlu Yazar: serdar.dizman@erdogan.edu.tr

Kabul Tarihi: 03.10.2017

Özet

Bu çalışmada, Rize ilinde bulunan Pileki Mağarası'ndan çıkarılan Pileki Taşı ve toprak örneklerinde iz element (Cr, Mn, $\mathrm{Fe}, \mathrm{Ni}, \mathrm{Cu}, \mathrm{Zn}$ ve $\mathrm{Pb}$ ) konsantrasyonları Enerji Dağılımlı X-Işını Floresans (EDXRF) spektrometresi ile belirlendi. Alınan örneklerde $\mathrm{Cr}, \mathrm{Mn}, \mathrm{Fe}, \mathrm{Ni}, \mathrm{Cu}, \mathrm{Zn}$ ve $\mathrm{Pb}$ elementleri için ortalama konsantrasyonlar sırasıyla toprak örnekleri için 49.63 $\pm 4.13,1255.26 \pm 14.73,88534.43 \pm 646.01,26.19 \pm 1.94,248.02 \pm 3.34,85.06 \pm 1.55$ ve $33.98 \pm 0.89 \mathrm{mg} / \mathrm{kg}, \mathrm{pileki}$ taş1 örnekleri için $28.06 \pm 2.13,803.89 \pm 10.28,59555.64 \pm 534.40,23.56 \pm 1.51,150.27 \pm 2.88,58.95 \pm 1.01$ ve $32.10 \pm$ $1.20 \mathrm{mg} / \mathrm{kg}$ olarak bulundu. Toprak örnekleri için elde edilen konsantrasyonlar $\mathrm{Mn}$ ve Cu konsantrasyonları hariç dünya topraklarında gözlenen sınır değerler içerisinde bulunmuştur. Ayrıca, çalışılan örnekler için elde edilen konsantrasyon değerleri, dünyanın farklı bölgelerinde yapılan çalışmalarla karşılaştırıldı.

Anahtar Kelimeler: EDXRF, Pileki Mağarası, Pileki Taşı, Toprak, İz elementleri, Rize

\section{Determination of Trace Elements in Pileki Stone and Soil Samples Obtained from Pileki Cave by Using EDXRF Spectrometer}

\begin{abstract}
In this study, concentrations of trace elements $(\mathrm{Cr}, \mathrm{Mn}, \mathrm{Fe}, \mathrm{Ni}, \mathrm{Cu}, \mathrm{Zn}$ and $\mathrm{Pb}$ ) were determined in Pileki Stone and soil samples obtained from Pileki Cave in Rize by Energy Dispersive X-Ray Fluorescence (EDXRF) spectrometry. The mean concentrations of $\mathrm{Cr}, \mathrm{Mn}, \mathrm{Fe}, \mathrm{Ni}, \mathrm{Cu}, \mathrm{Zn}$ and $\mathrm{Pb}$ elements in soil samples were $49.63 \pm 4.13,1255.26 \pm 14.73,88534.43$ $\pm 646.01,26.19 \pm 1.94,248.02 \pm 3.34,85.06 \pm 1.55$ and $33.98 \pm 0.89 \mathrm{mg} / \mathrm{kg}$, respectively and they were found to be 28.06 $\pm 2.13,803.89 \pm 10.28,59555.64 \pm 534.40,23.56 \pm 1.51,150.27 \pm 2.88,58.95 \pm 1.01$ and $32.10 \pm 1.20 \mathrm{mg} / \mathrm{kg}$ for pileki stone samples. Concentrations obtained for soil samples were found to be within the limit values observed in world soils except $\mathrm{Mn}$ and $\mathrm{Cu}$ concentrations. In addition, the concentration values obtained for the studied samples were compared to the studies conducted in different regions of the world.
\end{abstract}

Keywords: EDXRF, Pileki Cave, Pileki Stone, Soil, Trace elements, Rize

\footnotetext{
† Bu çalışmanın bir bölümü 29. Uluslararası Fizik Kongresi’nde özet bildiri olarak sunulmuştur.
} 


\section{Giriş}

Karadeniz yöresi mutfak kültüründe, küle gömerek ekmek pişirme geleneği çok eskilere dayanmaktadır. Bu mutfak kültüründe ekmekler ateşin yakıldığı yerde, pileki adı verilen ve doğal taştan yapılan bu kaplar içerisinde gömme usulü ile pişirilirler. Pileki, işlenebilen, ısıyı ileten, ısınınca çatlamayan, homojen dokulu, su ve havayla temasta bozuşmayan kayalardan elde edilmektedir (Uzun ve Uzun, 2001; Demir, 2012; Önal, 2013; Kazancı ve Gürbüz, 2014). Kalın tabakalı, homojen elemanlı, kırıksız ve küresel ayrışma özelliğine sahip kayalar tercih edilen düzeylerdir. Tandır gibi işlev görebilen ve ekmek pişirmede yararlanılan pilekiler, 1970'lere kadar Karadeniz Bölgesi'nin kırsal kesimlerinde yaygın olarak kullanılmıştır. Şekil 1'de pileki ile pişirilen bir mısır ekmeği görülmektedir. Eskiden ekmek pişirmede vazgeçilmez araç pilekilermiş. Bugün bile Rize ilinin bazı yerlerinde pileki ile ekmek pişirilmektedir. Pilekiler Rize'nin İyidere ilçesinde bulunan Pileki mağarasından çıkarılmaktadır. Pileki mağarası, Karadeniz yöresi eski mutfak kültürünün izlerini taşımasının yanında doğal güzelliği ile de korunması gereken jeolojik miras niteliğindedir (Şaroğlu ve ark., 2010). Pileki Mağarası müzeye dönüştürülerek turizme kazandırılmıştır.

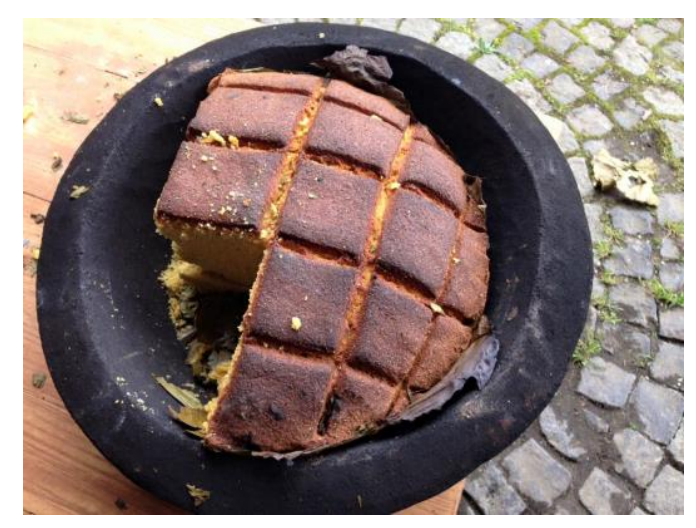

Şekil 1. Pileki ile pişirilmiş mısır ekmeği

İnsanlar tarafından kullanılan taşlar ve topraklardaki metal içeriklerinin araştırılması ve bunlara maruz kalma ile oluşabilecek riskler, çevresel yönetim süreçlerinde ve insan sağlığının genel olarak korunmasında oldukça önemlidir (Biasioli ve ark., 2007; De Miguel ve ark., 2007; Mielke ve ark., 2010). Çinko, krom, bakır, kobalt ve demir gibi iz elementleri hem bitkiler hem de insanlar için faydalıdır ancak her bir element belirli eşik değerlerinden daha fazla konsantrasyonlarda alınırsa toksik etkiler gösterebilir (Diaz Rizo ve ark., 2011). Özellikle çocuklarda merkezi sinir sistemini etkileyen ve başka hastalıkların ortaya çıkmasında rol oynayan kurşun, kadmiyum, civa ve benzeri ağır toksik elementler, ciddi bir çevresel sağlık problemi olmaya devam etmektedirler (Brewster ve Perazella, 2004; Navas-Acien ve ark., 2007). 
Toprak ve özellikle insanlar tarafından kullanılan pileki gibi taşların metal içeriklerinin değerlendirilmesi, insan sağlı̆̆ının genel olarak korunması ve çevresel olarak izlenmesi için önemlidir. Topraklardaki metal konsantrasyonları, hem doğal süreçlerle hem de insan kaynaklı olarak üretildiklerinden dolayı oldukça değişskendir.

$\mathrm{Bu}$ çalışmanın amacı, Pileki Mağarası'ndan çıkarılan pileki taşı ve toprak örneklerini metal kirliliği ve çevresel kalite açısından değerlendirmek ve bulunan sonuçları literatürdeki diğer verilerle karşılaştırmaktır. Bu çalışmanın sonuçları, Pileki Mağarası'nın çevresel olarak kirlenmesi üzerine başlangıç referans veriler olarak kullanılabilecektir.

\section{Materyal ve Metot}

\section{1. Çalışma Bölgesi}

Pileki mağarası, Rize il merkezinden 24 km uzaklıkta olup İyidere ilçesinin sınırları içerisinde yer almaktadır (Şekil 2). Pileki mağarası, 40 59' 23.6" Kuzey ile 40²2' 29.9" Doğu koordinatlarında bulunmakta olup rakımı 230 metredir (Şaroğlu ve ark., 2010; Nazik ve ark., 2008). 2013 y1lında turizme açılan mağarayı yılda yaklaşık 2000 kişi ziyaret etmektedir (URL-1). Mağaranın uzunluğu yaklaşık 1500 metredir.

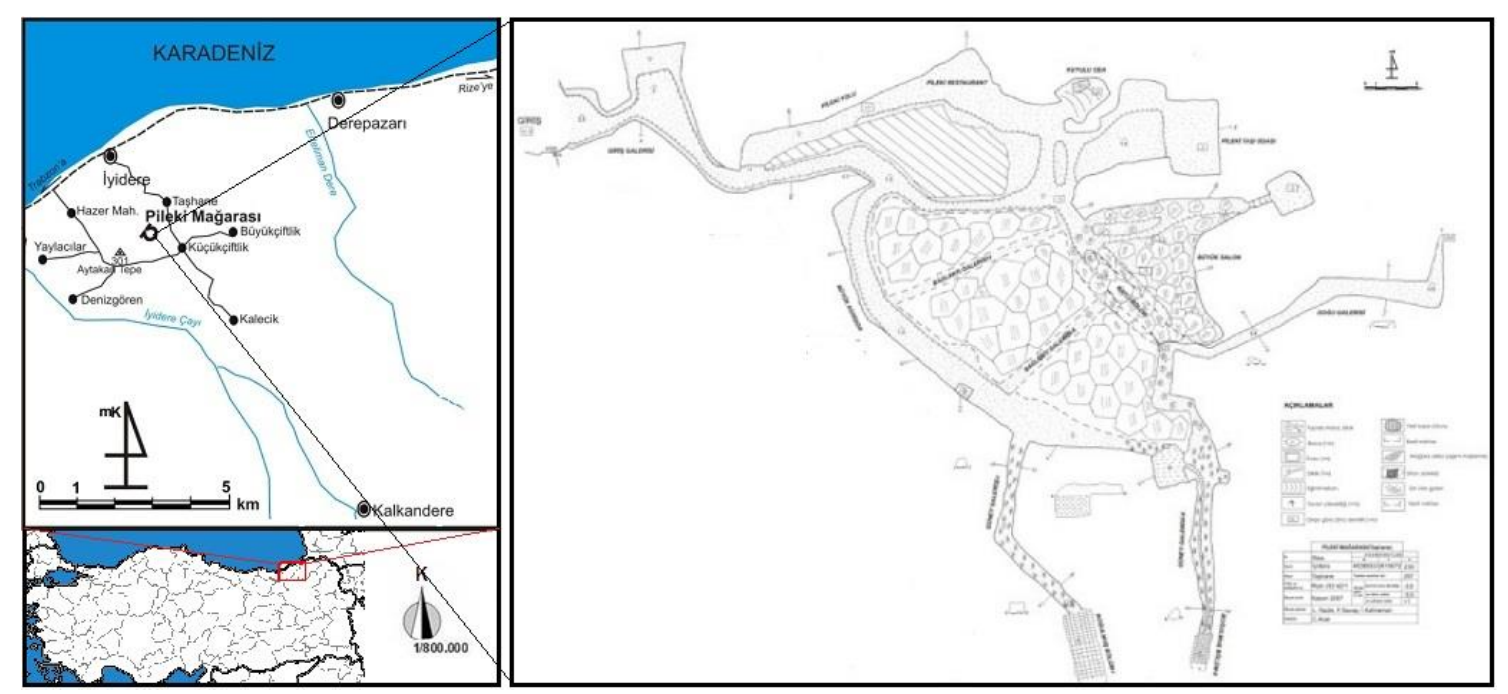

Şekil 2. Pileki mağarasının konumu ve krokisi

\section{2. Örneklerin Toplanması ve Analize Hazırlanması}

Pileki taşı ve toprak örnekleri, mağara dışından gelmesi muhtemel kontaminasyonları engellemek için mağara girişinden yaklaşık 20 m sonra alınmıştır. Mağaranın 20 metresinden itibaren 
30'ar metre arayla (20,50,80,110, 140 ve 170. metrelerde) 6 adet toprak, 6 adet te pileki taş1 numunesi alınmıştır. Toprak örnekleri, herhangi bir yüzey kirliliğini elimine etmek için $5 \mathrm{~cm}$ derinden alınmıştır. Yaklaşık $2 \mathrm{~kg}$ arasında alınan numuneler, etiketlenmiş temiz naylon poşetlere konularak laboratuvara ulaştırılmıştır. Pileki taşı ve toprak örnekleri, etüvde $105^{\circ} \mathrm{C}$ 'de 24 saat boyunca kurutuldu (Dizman, 2016). Kurutulan toprak numuneleri direkt olarak, pileki taşı numuneleri ise halkalı öğütücüde (Zhonghe, ZHM-1T) ögütüldükten sonra parçacık boyutu etkisini azaltmak için $400(37 \mu \mathrm{m})$ meshlik elekten geçirildi. Daha sonra örnekler ilk olarak agatta 1:4 oranında borik asitle $\left(\mathrm{H}_{3} \mathrm{BO}_{3}\right)$ homojen bir karışım oluncaya kadar karıştırıldı (borik asit, örnek tozlarının birbirlerine daha iyi yapışmasını, küçük fiziksel darbeler karşısında kırılmamasını ve yüzeyin çiziklere karşı mukavemetini artırmayı sağlar) ve ardından EDXRF spektrometresinde (Epsilon 5, Panalytical) analiz edilebilmesi için hidrolik press makinesinde $20 \mathrm{~s}$ boyunca 7 tonluk basınç uygulanarak $40 \mathrm{~mm}$ çapında pellet haline getirildi ( Ravisankar ve ark., 2011; Görür ve ark., 2012).

\subsection{Enerji Dağılımlı X-Işını Floresans (EDXRF) Spektrometresi Tekniği}

Bir X-Işınları Floresan Spektrometresinde, X-ışınları kaynağından çıkan fotonlar, kimyasal analizi yapılacak olan örnek üzerine gönderilir. Örneğin atomları ile etkileşen fotonlar, yeterli kinetik enerjiye sahip olmaları halinde, atomun iç kabuğundan bir elektronu yerinden çıkartıp, atomu temel durumdan yüksek enerji seviyesine getirir. Üst kabuklardan bir elektronun bu boşluğu doldurması ile enerji açığa çıkar ve atom tekrar temel haline döner. Açı̆̆a çıkan enerji karakteristik floresan 1şınımdır. Karakteristik ışınların dalga boyları sabittir ve elemente özgü olup bu durum örneğin kimyasal analizinin yapılmasına olanak tanır.

Enerji Dağılımlı X-Işını Floresans spektroskopisi (EDXRF) katı, sıvı, toz ve ince film gibi çeşitli malzemelerin elementsel bileşiminin belirlenmesi için kullanılan en basit, doğru ve ekonomik analitik yöntemlerden biridir. Bu teknik çok sayıda örnek tipleri için uygundur. Bu yöntemle uygun standart maddeler kullanılarak nicel analiz ppm düzeylerinden \% (yüzde) seviyesine kadar gerçekleştirilebilir. EDXRF spektrometresi ile Sodyum'dan (Na) Uranyum'a (U) kadar tüm elementlerin nitel ve nicel tayinleri yapılabilmektedir. XRF tekniğinin günümüzde yaygın olarak kullanılmasının sebeplerinden biri numuneye zarar vermeden tahribatsız olarak ölçüm yapılabilmesidir. Katı, sıvı, toz hatta gaz durumlarında bile uygulanabilmektedir (Demirci ve ark., 1992). XRF tekniği atık mineraller, suyun çevresel analizi, madencilik, maden bilimi ve jeoloji ile birlikte gıda endüstrisi, metal, çimento, polimer ve plastiği kapsayan geniş bir uygulama alanını kapsar. XRF ayrıca eczacılık ve araştırmalar için de çok kullanışı bir analiz yöntemidir (Brouwer, 2003). 


\section{Bulgular ve Tartışma}

Pileki mağarasından alınan toprak örneklerinde bazı iz elementleri $(\mathrm{Cr}, \mathrm{Mn}, \mathrm{Fe}, \mathrm{Ni}, \mathrm{Cu}, \mathrm{Zn}$ ve $\mathrm{Pb}$ ) için bulunan konsantrasyon sonuçları Tablo 1'de verilmektedir. Toprak örneklerinde $\mathrm{Cr}, \mathrm{Mn}, \mathrm{Fe}$, $\mathrm{Ni}, \mathrm{Cu}, \mathrm{Zn}$ ve Pb konsantrasyonları sirasıyla 37.83 - 73.06, 1187.37 - 1454.07, 83564.15 - 91324.94, 23.95 - 27.65, 221.14 - 351.83, 74.02 - 116.64 ve 26.66 - $49.60 \mathrm{mg} / \mathrm{kg}$ aralığında değişmekte olup ortalama değerleri $49.63 \pm 4.13,1255.26 \pm 14.73,88534.43 \pm 646.01,26.19 \pm 1.94,248.02 \pm 3.34$, $85.06 \pm 1.55$ ve $33.98 \pm 0.89 \mathrm{mg} / \mathrm{kg}$ olarak bulunmuştur. Aubert ve Pinta (1980) ile Fiedler ve Rösler (1988) tarafından dünya topraklarının metal konsantrasyonları Cr için 5-100, Mn için 500-1000, Fe için 200-100000, Ni için 40, Cu için 20, Zn için 10-300 ve Pb için 0.1-150 mg/kg olarak belirtilmiştir. $\mathrm{Bu}$ çalışmada, $\mathrm{Mn}$ ve $\mathrm{Cu}$ konsantrasyonları hariç diğer element konsantrasyonları dünya topraklarında gözlenen sınır değerler içerisindedir. Metalce zengin topraklarda Mn konsantrasyonlarının $10000 \mathrm{mg} / \mathrm{kg}, \quad \mathrm{Cu}$ konsantrasyonlarının ise $>2000 \mathrm{mg} / \mathrm{kg}$ olduğu belirtilmektedir (Aubert ve Pinta, 1980; Fiedler ve Rösler, 1988). Bu çalışmadaki topraklarda bulunan $\mathrm{Mn}$ ve $\mathrm{Cu}$ konsantrasyonları metalce zengin topraklardaki konsantrasyonlar düzeyindedir.

Tablo 1. Pileki mağarası toprak örneklerinde $\mathrm{Cr}, \mathrm{Mn}, \mathrm{Fe}, \mathrm{Ni}, \mathrm{Cu}, \mathrm{Zn}$ ve $\mathrm{Pb}$ elementlerinin konsantrasyon değerleri $(\mathrm{mg} / \mathrm{kg})$

\begin{tabular}{lccccccc}
\hline $\begin{array}{l}\text { Numune } \\
\text { Kodu }\end{array}$ & $\mathbf{C r}$ & $\mathbf{M n}$ & $\mathbf{F e}$ & $\mathbf{N i}$ & $\mathbf{C u}$ & $\mathbf{Z n}$ & $\mathbf{P b}$ \\
\hline MTN-1 & $43.47 \pm$ & $1454.07 \pm$ & $90480.76 \pm$ & $26.70 \pm$ & $351.83 \pm$ & $116.64 \pm$ & $49.60 \pm$ \\
& 2.95 & 19.50 & 517.58 & 1.82 & 5.64 & 1.44 & 0.97 \\
MTN-2 & $41.86 \pm$ & $1209.93 \pm$ & $88534.18 \pm$ & $23.95 \pm$ & $321.61 \pm$ & $85.52 \pm$ & $30.71 \pm$ \\
& 6.92 & 9.45 & 741.50 & 2.95 & 4.09 & 1.48 & 0.52 \\
MTN-3 & $37.83 \pm$ & $1187.37 \pm$ & $83564.15 \pm$ & $25.62 \pm$ & $222.34 \pm$ & $74.02 \pm$ & $36.74 \pm$ \\
& 5.16 & 7.13 & 619.32 & 1.53 & 4.29 & 1.41 & 0.55 \\
MTN-4 & $40.09 \pm$ & $1251.66 \pm$ & $88092.56 \pm$ & $26.18 \pm$ & $221.14 \pm$ & $83.96 \pm$ & $32.18 \pm$ \\
& 4.64 & 6.38 & 834.00 & 1.89 & 1.22 & 1.84 & 1.85 \\
MTN-5 & $73.06 \pm$ & $1226.35 \pm$ & $91324.94 \pm$ & $27.04 \pm$ & $230.43 \pm$ & $75.51 \pm$ & $27.95 \pm$ \\
& 2.90 & 23.10 & 387.08 & 1.21 & 2.61 & 1.41 & 0.87 \\
MTN-6 & $61.48 \pm$ & $1202.16 \pm$ & $89209.99 \pm$ & $27.65 \pm$ & $230.77 \pm$ & $74.69 \pm$ & $26.66 \pm$ \\
Dünya & 2.22 & 22.82 & 776.59 & 2.21 & 2.18 & 1.75 & 0.56 \\
Topraklar1 & $5-100$ & $500-1000$ & $200-100000$ & 40 & 20 & $10-300$ & $0.1-150$ \\
\hline
\end{tabular}

MTN: Mağara Toprağı Numunesi

Pileki mağarasından alınan pileki taşı örneklerinde $\mathrm{Cr}, \mathrm{Mn}, \mathrm{Fe}, \mathrm{Ni}, \mathrm{Cu}, \mathrm{Zn}$ ve $\mathrm{Pb}$ elementlerinin konsantrasyon değerleri Tablo 2'de verilmektedir. Pileki taşı örneklerinde $\mathrm{Cr}, \mathrm{Mn}, \mathrm{Fe}, \mathrm{Ni}, \mathrm{Cu}, \mathrm{Zn}$ ve Pb konsantrasyonları sirasiyla 19.72 - 35.69, 673.86 - 917.49, 47203.16 - 71056.93, 18.46 - 30.78, $117.05-179.75,53.99-65.09$ ve $18.75-49.84 \mathrm{mg} / \mathrm{kg}$ aralığında değişmekte olup ortalama değerleri $28.06 \pm 2.13,803.89 \pm 10.28,59555.64 \pm 534.40,23.56 \pm 1.51,150.27 \pm 2.88,58.95 \pm 1.01$ ve 32.10 $\pm 1.20 \mathrm{mg} / \mathrm{kg}$ olarak bulunmuştur. 
Tablo 2. Pileki taşı örneklerinde $\mathrm{Cr}, \mathrm{Mn}, \mathrm{Fe}, \mathrm{Ni}, \mathrm{Cu}, \mathrm{Zn}$ ve $\mathrm{Pb}$ elementlerinin konsantrasyon değerleri (mg/kg)

\begin{tabular}{|c|c|c|c|c|c|c|c|}
\hline $\begin{array}{l}\text { Numune } \\
\text { Kodu }\end{array}$ & $\mathrm{Cr}$ & Mn & $\mathrm{Fe}$ & $\mathbf{N i}$ & $\mathrm{Cu}$ & $\mathbf{Z n}$ & $\mathbf{P b}$ \\
\hline PTN-1 & $\begin{array}{c}30.07 \pm \\
3.94\end{array}$ & $\begin{array}{c}846.71 \pm \\
13.21\end{array}$ & $\begin{array}{c}63264.41 \pm \\
1141.56\end{array}$ & $\begin{array}{c}30.78 \pm \\
0.30\end{array}$ & $\begin{array}{c}157.88 \pm \\
2.21\end{array}$ & $\begin{array}{c}57.31 \pm \\
0.63\end{array}$ & $\begin{array}{c}20.28 \pm \\
1.58\end{array}$ \\
\hline PTN-2 & $\begin{array}{c}31.50 \pm \\
3.34\end{array}$ & $\begin{array}{c}673.86 \pm \\
9.31\end{array}$ & $\begin{array}{c}47203.16 \pm \\
237.86\end{array}$ & $\begin{array}{c}20.63 \pm \\
1.08\end{array}$ & $\begin{array}{c}117.05 \pm \\
1.99\end{array}$ & $\begin{array}{c}61.08 \pm \\
1.33\end{array}$ & $\begin{array}{c}18.75 \pm \\
0.43\end{array}$ \\
\hline PTN-3 & $\begin{array}{c}20.68 \pm \\
1.51\end{array}$ & $\begin{array}{c}734.68 \pm \\
11.01\end{array}$ & $\begin{array}{c}53324.38 \pm \\
293.41\end{array}$ & $\begin{array}{c}18.46 \pm \\
2.42\end{array}$ & $\begin{array}{c}174.68 \pm \\
3.56\end{array}$ & $\begin{array}{c}53.99 \pm \\
0.91\end{array}$ & $\begin{array}{c}49.84 \pm \\
2.56\end{array}$ \\
\hline PTN-4 & $\begin{array}{c}30.68 \pm \\
1.15\end{array}$ & $\begin{array}{c}834.54 \pm \\
4.47\end{array}$ & $\begin{array}{c}63082.19 \pm \\
347.31\end{array}$ & $\begin{array}{c}24.09 \pm \\
0.85\end{array}$ & $\begin{array}{c}123.53 \pm \\
2.63\end{array}$ & $\begin{array}{c}60.10 \pm \\
0.81\end{array}$ & $\begin{array}{c}43.48 \pm \\
0.73\end{array}$ \\
\hline PTN-5 & $\begin{array}{c}19.72 \pm \\
1.77\end{array}$ & $\begin{array}{c}816.09 \pm \\
10.01\end{array}$ & $\begin{array}{c}59402.79 \pm \\
383.21\end{array}$ & $\begin{array}{c}21.27 \pm \\
1.48\end{array}$ & $\begin{array}{c}148.74 \pm \\
1.53\end{array}$ & $\begin{array}{c}56.15 \pm \\
1.19\end{array}$ & $\begin{array}{c}28.66 \pm \\
0.43\end{array}$ \\
\hline PTN-6 & $\begin{array}{c}35.69 \pm \\
1.06\end{array}$ & $\begin{array}{c}917.49 \pm \\
13.71\end{array}$ & $\begin{array}{c}71056.93 \pm \\
803.04\end{array}$ & $\begin{array}{c}26.13 \pm \\
2.94\end{array}$ & $\begin{array}{c}179.75 \pm \\
5.33\end{array}$ & $\begin{array}{c}65.09 \pm \\
1.18\end{array}$ & $\begin{array}{c}31.57 \pm \\
1.46\end{array}$ \\
\hline
\end{tabular}

PTN: Pileki Taşı Numunesi

Pileki mağarasından alınan toprak örneklerinde $\mathrm{Cr}, \mathrm{Mn}, \mathrm{Fe}, \mathrm{Ni}, \mathrm{Cu}, \mathrm{Zn}$ ve $\mathrm{Pb}$ elementleri için bulunan ortalama konsantrasyon değerleri ile litaratürdeki başka çalışmalarda rapor edilen değerler Tablo 3'te verilmiştir.

Tablo 3. Literatürde toprak örnekleri için rapor edilen metal konsantrasyonları (mg/kg)

\begin{tabular}{lcccccccl}
\hline Ülke & $\mathbf{C r}$ & $\mathbf{C u}$ & $\mathbf{F e}$ & $\mathbf{M n}$ & $\mathbf{N i}$ & $\mathbf{P b}$ & $\mathbf{Z n}$ & Referans \\
\hline Rize, Türkiye & 50 & 248 & 88534 & 1255 & 26 & 34 & 85 & Bu çalışma \\
Havana, Küba & - & 101 & - & - & 66 & 101 & 240 & Diaz Rizo ve ark., 2011 \\
Missouri, USA & - & 18 & - & - & 16 & 49 & 95 & Ikem ve ark., 2008 \\
Torino, İtalya & - & 90 & - & - & 185 & 169 & 182 & Biasioli ve ark., 2007 \\
Ankara, Türkiye & - & 250 & - & - & 78 & 158 & 200 & Yay ve ark., 2008 \\
Hindistan & 79 & 148 & 194000 & 3050 & 145 & 43 & 129 & Pendias ve ark., 2001 \\
Tokat, Türkiye & 32 & 38 & 10344 & 320 & 54 & 45 & 60 & Tüzen, 2003 \\
Ürdün & 84 & - & - & - & - & 62 & 147 & Banat ve ark., 2005 \\
Van, Türkiye & - & 20 & - & 171 & 22 & 80 & 12 & Türkdoğan ve ark., 2002 \\
\hline
\end{tabular}

$\mathrm{Bu}$ çalışmada toprak örnekleri için bulunan $\mathrm{Cr}$ değeri Pendias ve arkadaşları ile Banat ve arkadaşlarının buldukları değerlerden, $\mathrm{Cu}$ değeri Yay ve arkadaşlarının buldukları değerden, Fe ve Mn değerleri Pendias ve arkadaşlarının buldukları değerden, Ni değeri Diaz Rizo ve arkadaşları, Biasioli ve arkadaşları, Yay ve arkadaşları, Pendias ve arkadaşları ile Tüzen tarafindan bulunan değerlerden, $\mathrm{Pb}$ değeri Tablo 3'de yer alan literatür çalışmalarındaki değerlerden, Zn değeri ise Diaz Rizo ve arkadaşları, Ikem ve arkadaşları, Biasioli ve arkadaşları, Yay ve arkadaşları, Pendias ve arkadaşları ile Banat ve arkadaşları tarafından bulunan değerlerden düşük bulunmuştur. Yine bu çalışmada bulunan $\mathrm{Cr}$ değeri Tüzen tarafindan bulunan değerden, $\mathrm{Cu}$ değeri Diaz Rizo ve arkadaşları, Ikem ve arkadaşları, Biasioli ve arkadaşları, Pendias ve arkadaşları, Türkdoğan ve arkadaşları ile Tüzen tarafından bulunan değerlerden, Fe değeri Tüzen tarafından bulunan değerden, Mn değeri 
Türkdoğan ve arkadaşları ile Tüzen tarafından bulunan değerlerden, Ni değeri Ikem ve arkadaşları ile Türkdoğan ve arkadaşları tarafından bulunan değerlerden, Zn değeri ise Türkdoğan ve arkadaşları ile Tüzen tarafından bulunan değerlerden yüksek bulunmuştur.

$\mathrm{Bu}$ çalışmada, Pileki taşı örneklerinde $\mathrm{Cr}, \mathrm{Mn}, \mathrm{Fe}, \mathrm{Ni}, \mathrm{Cu}, \mathrm{Zn}$ ve $\mathrm{Pb}$ elementleri için bulunan ortalama konsantrasyon değerleri ile litaratürdeki başka çalışmalarda rapor edilen değerler Tablo 4 'te verilmiştir.

Tablo 4. Türkiye ve farklı ülkelerde bazı taş örnekleri için rapor edilen metal konsantrasyonları (mg/kg)

\begin{tabular}{lcccccccl}
\hline Ülke & $\mathbf{C r}$ & $\mathbf{C u}$ & $\mathbf{F e}$ & $\mathbf{M n}$ & $\mathbf{N i}$ & $\mathbf{P b}$ & $\mathbf{Z n}$ & Referans \\
\hline Rize, Türkiye & 28 & 150 & 59556 & 804 & 24 & 32 & 92 & Bu çalışma \\
Peru & 185 & 22 & - & - & 30 & 6 & 153 & Bech ve ark., 2010 \\
Pakistan & 40 & 9 & - & 221 & 25 & 67 & 10 & Javied ve ark., 2009 \\
Bulgaristan & 30 & 29 & - & 467 & 22 & 24 & 60 & Christova ve ark., 2007 \\
Japonya & 150 & 300 & - & - & 47 & 20 & 300 & Ishikawa ve ark., 1971 \\
Çin & 30 & 10 & - & - & 3 & 9 & 138 & Liang ve ark., 2000 \\
Mardin, Türkiye & - & 62 & 152 & 183 & 5 & 6 & 15 & Aydın ve ark., 2010 \\
Brezilya & 70 & 96 & - & - & 117 & 44 & 326 & Conceiçao ve ark., 2006 \\
\hline
\end{tabular}

$\mathrm{Bu}$ çalışmada pileki taşı örnekleri için bulunan $\mathrm{Cr}$ değeri Tablo 3'de yer alan literatür çalışmalarındaki değerlerden, $\mathrm{Cu}$ değeri Ishikawa arkadaşlarının buldukları değerden, Ni değeri Bech ve arkadaşları, Javied ve arkadaşları, Ishikawa ve arkadaşları ile Conceiçao ve arkadaşları tarafından bulunan değerlerden, $\mathrm{Pb}$ değeri Javied ve arkadaşları ile Conceiçao ve arkadaşları tarafindan bulunan değerlerden ve Zn değeri ise Bech ve arkadaşları, Ishikawa ve arkadaşları, Liang ver arkadaşları ile Conceiçao ve arkadaşları tarafından bulunan değerlerden düşük bulunmuştur. Yine yapılan bu çalışma ile bulunan $\mathrm{Cu}$ değeri Bech ve arkadaşları, Javied ve arkadaşları, Christova ve arkadaşları, Liang ve arkadaşları, Aydın ve arkadaşları ile Conceiçao ve arkadaşları tarafından bulunan değerlerden, Fe değeri Aydın ve arkadaşları tarafından bulunan değerden, Fe değeri Tüzen tarafından bulunan değerden, Mn değeri Tablo 3'de yer alan literatür çalışmalarındaki değerlerden, Ni değeri Christova ve arkadaşları, Liang ve arkadaşları ile Aydın ve arkadaşları tarafından bulunan değerlerden, $\mathrm{Pb}$ değeri Bech ve arkadaşları, Christova ve arkadaşları, Ishikawa ve arkadaşları, Liang ve arkadaşları ile Aydın ve arkadaşları tarafından bulunan değerlerden, Zn değeri ise Javied ve arkadaşları, Christova ve arkadaşları ile Aydın ve arkadaşları tarafindan bulunan değerlerden yüksek bulunmuştur. 


\section{Sonuçlar ve Öneriler}

Pileki mağarasından alınan örneklerde $\mathrm{Cr}, \mathrm{Mn}, \mathrm{Fe}, \mathrm{Ni}, \mathrm{Cu}, \mathrm{Zn}$ ve $\mathrm{Pb}$ elementleri için bulunan ortalama konsantrasyonlar sırasıyla toprak örnekleri için 49.63 $\pm 4.13,1255.26 \pm 14.73,88534.43 \pm$ $646.01,26.19 \pm 1.94,248.02 \pm 3.34,85.06 \pm 1.55$ ve $33.98 \pm 0.89 \mathrm{mg} / \mathrm{kg}$, pileki taş1 örnekleri için ise $28.06 \pm 2.13,803.89 \pm 10.28,59555.64 \pm 534.40,23.56 \pm 1.51,150.27 \pm 2.88,58.95 \pm 1.01$ ve 32.10 $\pm 1.20 \mathrm{mg} / \mathrm{kg}$ olarak bulunmuştur. Pileki taşı ve toprak örneklerinde $\mathrm{Cr}, \mathrm{Mn}, \mathrm{Fe}, \mathrm{Ni}, \mathrm{Cu}, \mathrm{Zn}$ ve $\mathrm{Pb}$ elementleri için bulunan ortalama konsantrasyonlar Şekil 3'te gösterilmektedir.

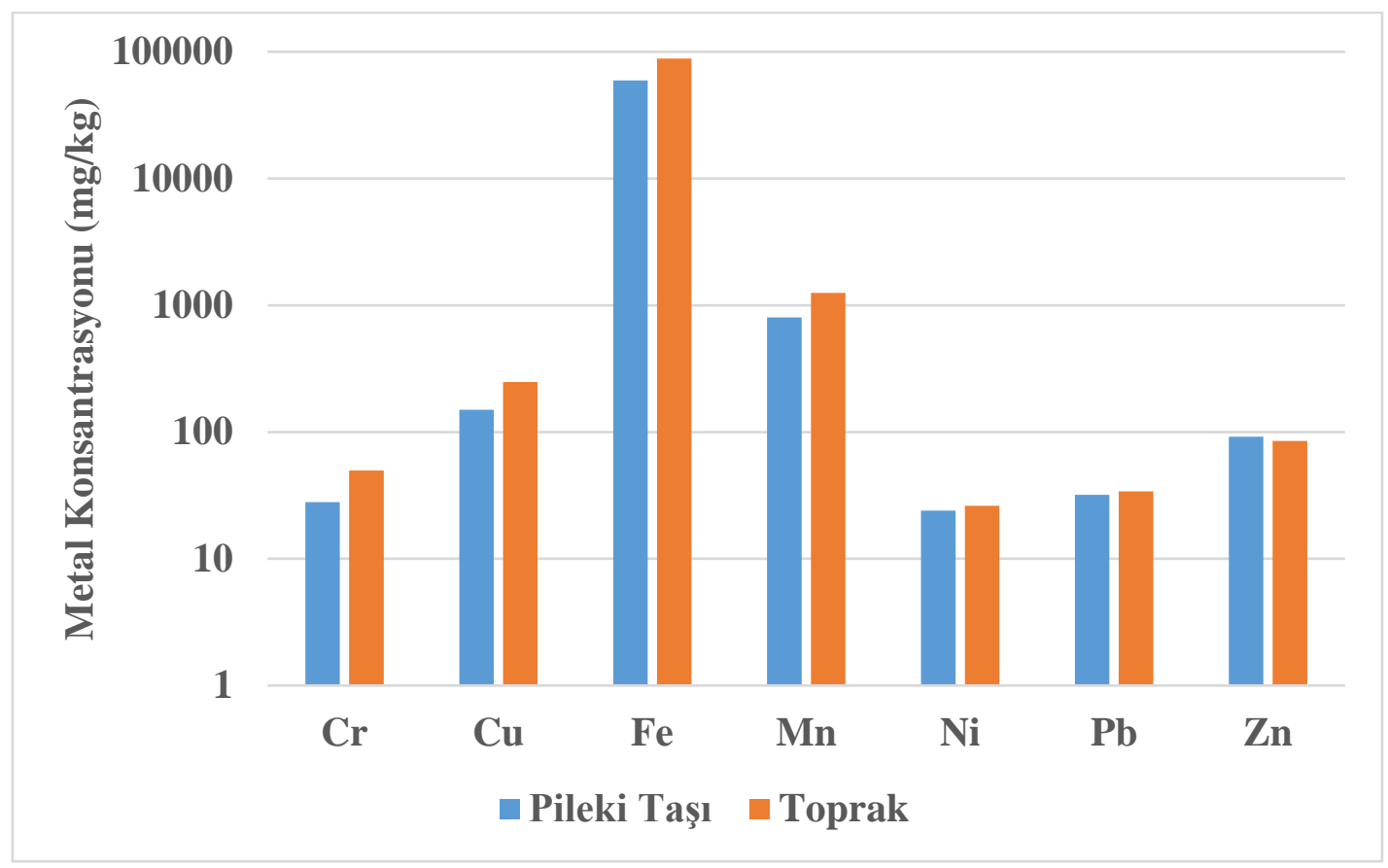

Şekil 3. Pileki taşı ve toprak örneklerinde metal konsantrasyonları

Toprak örneklerinde, $\mathrm{Mn}$ ve $\mathrm{Cu}$ konsantrasyonları hariç diğer element konsantrasyonları dünya topraklarında gözlenen sınır değerler içerisinde bulunmuştur. Toprak örneklerinde bulunan $\mathrm{Cr}, \mathrm{Mn}$, $\mathrm{Fe}, \mathrm{Ni}, \mathrm{Cu}, \mathrm{Zn}$ ve $\mathrm{Pb}$ konsatrasyonları $\mathrm{Zn}$ hariç Pileki taşında bulunan konsantrasyonlardan daha yüksektir. Ayrıca, bu çalışma ile bulunan $\mathrm{Cr}, \mathrm{Mn}, \mathrm{Fe}, \mathrm{Ni}, \mathrm{Cu}, \mathrm{Zn}$ ve $\mathrm{Pb}$ elementlerinin ortalama konsantrasyon değerleri, farklı ülkelerde yapılmış çalışmalardaki literatür değerleriyle kıyaslanmıştır.

Çevre ve Şehircilik Bakanlığı tarafından hazırlanan ve Resmi Gazete'de yayınlanan “Toprak Kirliliği Yönetmeliği”nde toprakta müsaade edilen ağır metal sınır değerleri kurşun için $300 \mathrm{mg} / \mathrm{kg}$, krom için $100 \mathrm{mg} / \mathrm{kg}$, bakır için $140 \mathrm{mg} / \mathrm{kg}$, nikel için $75 \mathrm{mg} / \mathrm{kg}$ ve çinko için $300 \mathrm{mg} / \mathrm{kg}$ olarak verilmiştir (TKY, 2005). Bu çalışma ile Pileki mağarası toprağında belirlenen ağır metal değerleri belirtilen sınır değerlerden düşük bulunmuştur. Dolayısıyla, mağara toprağının ağır metal yönünden 
kirlenmediği söylenebilir. Bunun yanında, elde edilen deneysel veriler ile pileki taşından yapılma kapları kullanan insanlar için ağır metallerin herhangi bir risk oluşturmayacağı da söylenebilir.

\section{Kaynaklar}

Aubert, H. and Pinta, M., (1980). Trace Elements in Soils. Amsterdam: Elsevier Scientific Publishing Company.

Aydin, I., Aydin, F., Saydut, A., Bakirdere, E. G., and Hamamci, C., (2010). Hazardous metal geochemistry of sedimentary phosphate rock used for fertilizer (Mazıdag, SE Anatolia, Turkey). Microchemical Journal, 96, 247-251.

Banat, K.M., Howari, F.M., and Al-Hamada, A.A., (2005). Heavy metals in urban soils of central Jordan: Should we worry about their environmental risks. Environmental Research, 97, 258-273.

Bech, J., Suarez, M., Reverter, F., Tume, P., Sánchez, P., Bech, J., and Lansac, A., (2010). Selenium and other trace elements in phosphate rock of Bayovar-Sechura (Peru). Journal of Geochemical Exploration, 107, $136-14$.

Biasioli, M., Grcman, H., Kralj, T., Madrid, F., Diaz-Barrientos, E., and Ajmone-Marsan, F., (2007). Potentially toxic elements contamination in urban soils: a comparison of three European cities. J Environ Qual, 36, 70-79.

Brewster, UC. and Perazella, MA., (2004). A review of chronic lead intoxication: an unrecognized cause of chronic kidney disease. Am J Med Sci, 327(6), 341-347.

Brouwer, P., (2003). Theory of XRF, Netherlands: Panalytical B.V.

Christova, J., Christov, D., and Kuikin, S., (2007). Background contents of some minor and trace elements in the rocks on Bulgarian territory. Geologica Balcanica, 36(1-2), 65-76.

Conceicao, F.T. and Daniel Marcos Bonotto, D.M., (2006). Radionuclides, heavy metals and fluorine incidence at Tapira phosphate rocks, Brazil, and their industrial (by) products. Environmental Pollution, 139, 232243.

De Miguel, E., Iribarren, I., Chacon, E., Ordonez, A., and Charlesworth, S., (2007). Risk-based evaluation of the exposure of children to trace elements in playgrounds in Madrid (Spain). Chemosphere, 66, 505513.

Demir, N., (2012). www.necatidemir.net/images/demir/bkosem/bileki_pileki.pdf.

Demirci, Ş. ve Yalçınkaya, I., (1992). Karain Mağarasından elde dilen bazı toprak ve sediment örneklerinin analizi. Arkeometri sonuçları toplantısı VIII. (291-294), Ankara.

Diaz Rizo, O., Echeverria Castillo, F., Arado Lopez, J.O., and Hernandez Merlo, M., (2011). Assessment of Heavy Metal Pollution in Urban Soils of Havana City, Cuba. Bull Environ Contam Toxicol, 87, 414419.

Dizman, S., (2016). Natural Radioactivity Levels in Pileki Stone and Soil Samples Taken From Pileki Cave in Rize Province. Adıyaman University Journal of Science, 6 (2), 217-232.

Fiedler, H.J. and Rösler, H.J., (1988). Spurenelemente in der Umwelt. Stuttgart: Verlag Ferdinand Enke.

Ikem, A., Campbell, M., Nyirakahibi, I., and Garth, J., (2008). Baseline concentrations of trace elements in residential soils from Southeastern Missouri. Environ Monit Assess, 140, 69-81.

Ishikawa, H., Berman, S., and Yagi, K., (1971). Geochemical study of trace elements in the alkalic rocks of Nemuro Peninsula, Hokkaido, Japan. Geochemical Journal, 5, 187- 206.

Javied, S., Mehmood, T., Chaudhry, M.M., Tufail, M., and Irfan, N., (2009). Heavy metal pollution from phosphate rock used for the production of fertilizer in Pakistan. Microchemical Journal 91, 94-99.

Kazanc1, A. ve Gürbüz, A., (2014). Jeolojik miras nitelikli Türkiye doğal taşları, Türkiye Jeoloji Bülteni, 57(1), $19-44$.

Korkmaz Görür, F., Keser, R., Akçay, N., S. Dizman, S., (2012). Radioactivity and heavy metal concentrations of some commercial fish species consumed in the Black Sea Region of Turkey. Chemosphere, 87, 356361.

Mielke, H.W., Laidlaw, M.A.S., and Gonzales, C., (2010). Lead (Pb) legacy from vehicle traffic in eight California urbanized areas: continuing influence of lead dust on children's health. Sci Total Environ, 408, 3965-3975.

Navas-Acien, A., Guallar, E., Silbergeld, E.K., and Rothenberg, S.J., (2007). Lead exposure and cardiovascular disease a systematic review. Environ Health Perspect, 115(3), 472-482. 
Nazik, L., Savaş, F., Kahraman, İ., ve Acar, C., (2008). Pikeli mağarası (Taşhane) İyidere-Rize araştırma raporu, Maden Tetkik ve Arama Genel Müdürlüğü (MTA) Raporları, 11012.

Önal, Ü., (2013). Ekmeğimizi pişirdiğimiz bir araç; pileki. Bizim Ahıska, Kış 2013, 47-48.

Pendias, K. and Pendias, H., (2001). Trace elements in soils and plants. Newyork: CRC Press.

Qi Liang, Hu Jing and D. Conrad Gregoire. Determination of trace elements in granites by inductively coupled plasma mass spectrometry. Talanta 51 (2000) 507-513

Ravisankar, R., Chandrasekaran, A., Kiruba, S., Raghu, Y., Prasad, M.V.R., Satpathy, K. and Maheswaran, C., (2011). Energy dispersive X-Ray fluorescence (EDXRF) analysis of ancient potteries of Tamil Nadu. Arch Appl Sci Res, 3, 289-295.

Şaroğlu, F., Güner, Y., Nazik, L., ve Aksoy, B., (2010). Pileki mağarası ve jeokültürel değeri, 1. Uluslararas1 Jeolojik Sempozyumu ve Güneydoğu Avrupa Ülkeleri Pro GEO Toplantıs1 (34-35), Elazı̆̆g.

TKY, 2005. Toprak Kirliliği Yönetmeliği, 25831 sayılı Resmi Gazete.

Turkdogan, M.K., Kilicel, F., Kara, K., Tuncer, İ., ve Uygan, İ., (2002). Heavy metals in soil, vegetables and fruits in the endemic upper gastrointestinal cancer region of Turkey. Environmental Toxicology and Pharmacology, 13,175-179.

Tuzen, M., (2003). Determination of heavy metals in soil, mushroom and plant samples by atomic absorption spectrometry. Microchemical Journal, 74, 289-297.

URL-1: https://www.haberler.com/pileki-magarasi-ziyaretcilerini-bekliyor-5981412-haberi, (Erişim Tarihi: 12 Mayıs 2017).

Uzun, A. ve Uzun, S., (2001). Taşhaneden aşhaneye taş pilekiler. Osmangazi Üniversitesi Sosyal Bilimler Dergisi, 2, 149-168.

Yay, O.D., Alagha, O., and Tuncel, G., (2008). Multivariate statistics to investigate metal contamination in surface soil. Environ Manag, 86, 581-594. 